\title{
A Clinical Study of Efficacy of Limbal Stem Cell Transplantation in the Management of Pterygium.
}

\author{
Dr. MVDL Sathyanarayana. M.S Assistant professor of ophthalmology., \\ RIMS.,Kadapa. AP Dr. D. Manikanta PG.,RIMS., Kadapa., AP
}

\begin{abstract}
:
Aim: To study the efficacy of the limbal stem cell transplantation in the management of pterygium.

Methods: In an interventional case series, 50 patients with pterygium underwent surgical excision with limbalstem cell transplantation on to bare sclera at Rajiv Gandhi Institute of Medical Sciences, kadapa .Patients were followed for 6 months and results were evaluated in terms of recurrent growth and other postoperative complications.

Results: 50 eyes of 50 patients including 32 females and 18 males of mean age of $40 \pm 8$ years were operated on the pterygia extended onto cornea for more than $2 \mathrm{~mm}$. Only two eye withlimbal stem cell transplantation( $4 \%$ ) demonstrated recurrent pterygium growth.

Conclusion: Short term results suggest that pterygium excision withlimbal stem cell transplantation issafe and effective method. Recurrent growth is less and cosmetic appearance also better withlimbalstem cell transplantation. A larger randomized clinical trial with longer follow up period is however recommended.
\end{abstract}

Keywords: Pterygium,Limbal stem cell transplantation, Recurrence.

\section{Introduction}

Pterygium is a benign condition characterized by a wedge like fibro vascular growth of actinically damaged conjunctiva encroaching across limbus and invading the cornea. It is a common external eye condition, affecting different populations especially in tropical and subtropical regions . The primary indication for surgical removal of pterygium is decreased visual acuity, which can be the result of encroachment of the lesion onto the visual axis, induced irregular astigmatism, or breakup of precorneal tear film. Other indications for surgical intervention include discomfort and irritation unresponsive to conservative therapy, restricted ocular motility, difficulty with contact lens wear, anticipated keratorefractive surgery and for cosmetic reason.

Major adjuncts for prevention of pterygium recurrence are conjunctival or limbal auto grafts,amniotic membrane grafts, application of Mitomycin C,post operative beta irradiation, postoperative Thiotepa application, buccal mucus membrane grafting etc. .Although many other therapeutic modalities have been proposed, further studies on their efficacy and safety are required. The purpose of the current study is to find out the efficacy and outcome of pterygium excisionwithlimbal stem cell transplantation in terms of recurrence and complications.

\section{Materials and Methods}

This interventional case series was conducted from December 2015 to Novembert2016 at Rajiv Gandhi Institute of Medical sciences, Kadapa and included a consecutive series 50 eyes of 50 patients with pterygium extending at least $2 \mathrm{~mm}$ on to cornea. Data was collected in standardized proformas from all the patients who are willing to participate in study including taking history, physical and ocular examination and relevant investigations both preoperative and postoperative like visual acuity, slit lamp bio microscopy, Intraocular pressure measurement. Patients were followed for 6 months postoperatively.

\section{Inclusion Criteria:}

1) All patients $>18$ years age with pterygium, willing to participate in the study and given informed consent.

2)Ability to attend follow ups.

3) Pterygium $2 \mathrm{~mm}$ or more than $2 \mathrm{~mm}$ encroaching onto cornea.

\section{Exclusion Criteria:}

1)Age $<18$ years.

2)Pseudo pterygium.

3)Pterygium less than $2 \mathrm{~mm}$.

4)Lid abnormalities, trichiasis,entropion, ectropion.,coloboma of lids

5) Sac infection,Chronic conjunctivitis. 
6)Bell's palsy, Dry eye syndrome.

7)Patients with recurrent epithelial erosions.

\section{Surgical Procedure}

Anesthesia: Two point Peribulbar Infiltration anesthesia.

Under aseptic conditions, eye is draped \& speculum is inserted. Head of pterygium was first separated at limbus and dissected towards central cornea. After excising head, most of body and subconjunctival fibrovascular tissue is separated from overlying conjunctiva and excised. While excising medially, be caution not to damage Medial rectus. Residual fibro vascular tissue over cornea was detached using toothed forceps or by gentle scraping with \# 15 surgical blade. Conjunctiva above and below was trimmed to create a rectangular area of bare sclera.

Now the eye is turned down to approach the superior bulbar conjunctiva. The area of corresponding size is measured with calipers and exact dimensions marked with marker pen. These marks are included with in the graft tissue margins, during the excision of the donor tissue to facilitate its reorientation in the recipient site. The graft is thinly dissected, avoiding Tenon's tissue and episclera and stem cells gently separated at the limbus.After freeing, the graft is transferred to the recipient bed and secured to adjacent conjunctiva and episclera with blood clot.Antibiotic eye ointment applied in lower fornix and pad and bandage applied for 24 hours.
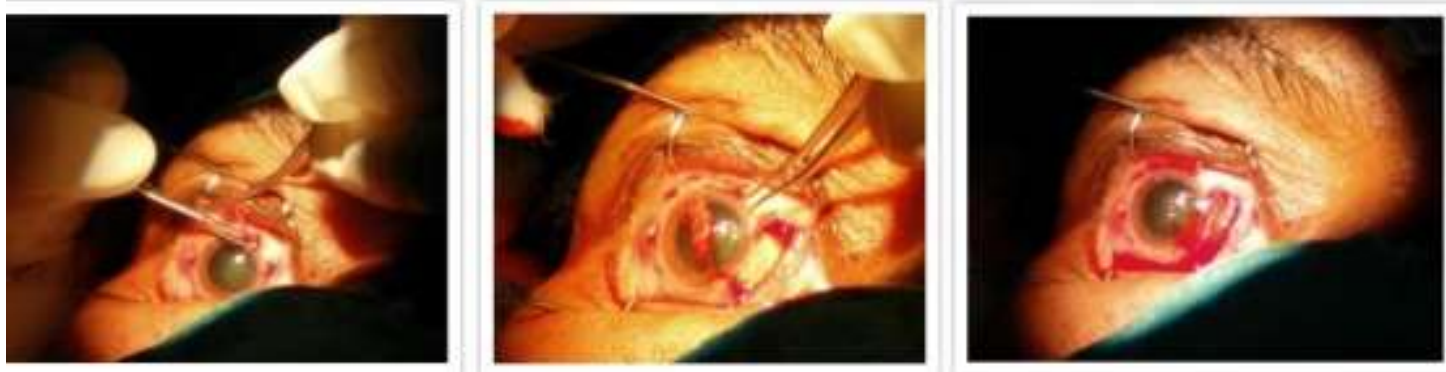

Postoperatively, Ciprofloxacin-Dexamethasone eye drops were given 6 times/day for 1week. Later Dexamethasone eye drops 4 times/day for one month, 2times/day for 10 days.

Post op follow up was done at 1st postoperative day, 1 week, 4 week, 6 week, 12 week,6Month post operatively.At each visit, complaints are enquired,looked for any complications.Slit lamp examination to monitor graft bed integrity and development of other complications.

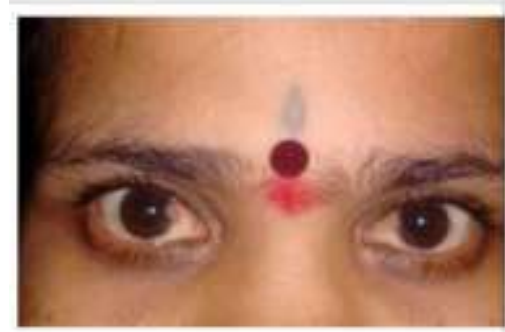

$\operatorname{Pre} o p($ R.E)

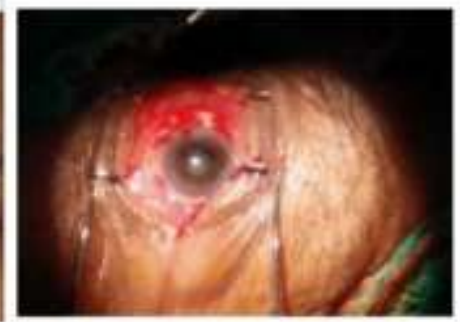

Intra op

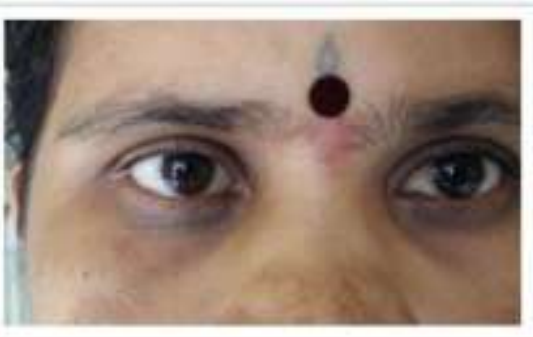

Post op( R.E)

\section{Results}

50 eyes with pterygia of 50 patients including 32 females and 18 males with mean age of $40 \pm 8$ years were operated. Theextent of pterygium invasion beyond $2 \mathrm{~mm}$ from limbus. On the first postoperative day, all patients had corneal epithelial defects .By one week, all epithelial defects healed completely and there was no corneal staining with fluorescein. Minor post operative complaints like watering noted in few people. Four patients out of 50 with stem cell trans plantation developed graft edema $(8 \%)$. One patient developed hemorrhage ( $2 \%)$. In two patients ( 2 out of 50 ) pterygium recurrence was noted (4\%). Recurrence may be due to use of very thin stem cell graft devoid of tenons tissue. No other adverse effects or complications occurs throughout the study period.Commonest complaints arewatering.No significant change in visual acuity or intraocular pressure is noted postoperatively. 


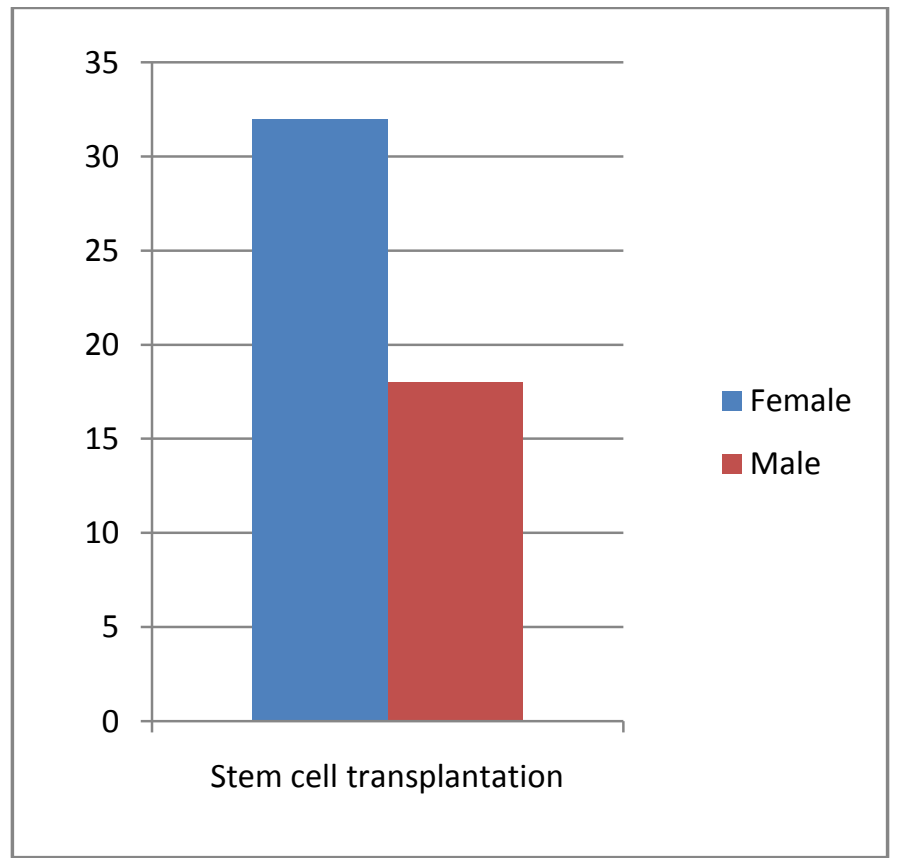

\section{Post-Op Complications In Limbal Stem Cell Transplantation.}

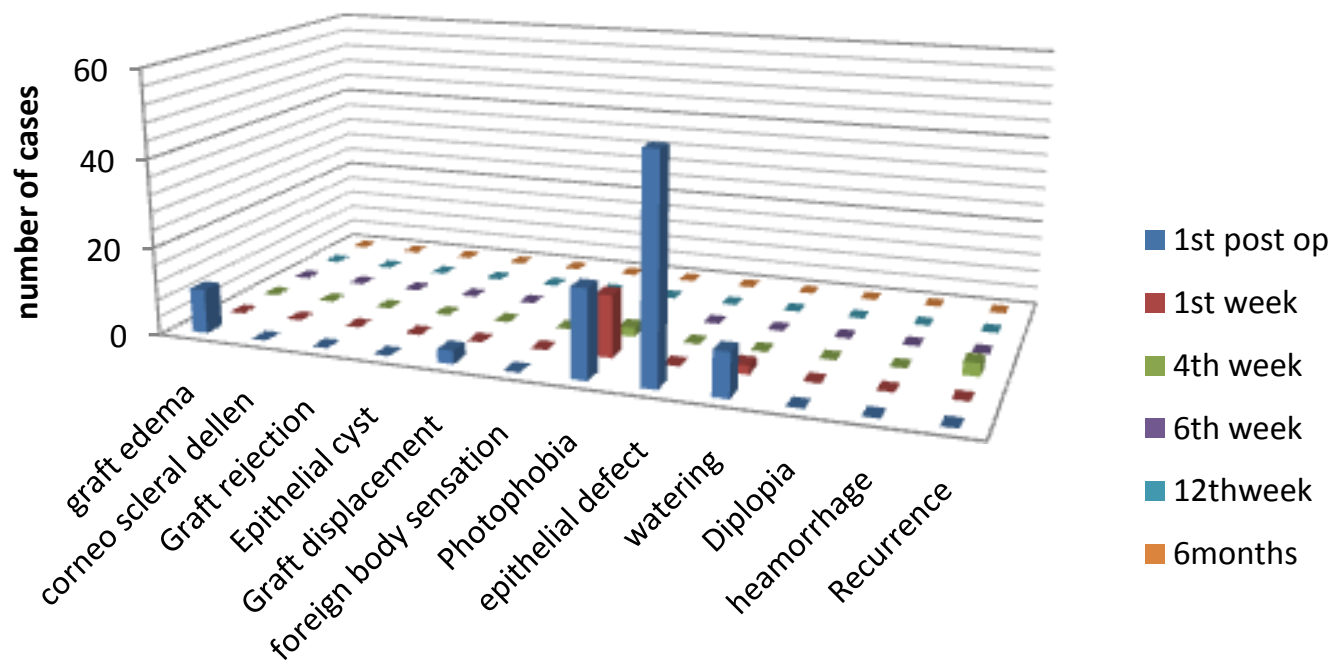

post operative complications

\section{Discussion}

A pterygium is a multifactorial degenerative disorder. Different procedures have been proposed for treatment of Pterygium. However, the main complication common to all is recurrent disease which is more difficult to control. The mechanism of pterygium recurrence has been attributed to surgical trauma, post- operative inflammation, proliferation of fibroblasts and deposition of extracellular matrix.

Recurrence rates are as high as $40 \%$ and $16.7 \%$ have been observed in the bare sclera and primary closure techniques, respectively. To reduce this recurrence rate, adjunctive limbal stem cell transplantation or Amniotic membrane graft or topical Mitomycin $\mathrm{C}$ could be used. Following pterygium excision with limbal stem cell transplantation recurrence rate of $7 \%$ have been reported. Topical mitomycin $\mathrm{C}$ has been used as a method of reducing recurrence. However, it has a recurrence rate of $38 \%$ which is comparatively high. Moreover, some vision threatening side effects such as scleral ulceration, cataract formation and glaucoma have been reported. 
Ocular surface describes the entire epithelial surface of the external eye encompassing the corneal epithelium as well as the bulbar and palpebral conjunctival epithelium,Initially considered as only an anatomic classification that organized the physical continuity of stratified non keratinizing epithelium of the conjunctiva, limbus, and cornea,the clinical and research insights of Friedenwald, Thoft and colleagues, and many others have offered compelling evidence of important functional relationships within this anatomic continuum.Crucial notion of the ocular surface as the functional unit has stimulated a complete reorganization of our approaches to the pathogenetic concept and the clinical management of ocular surface disease. Although the conjunctiva and especially the limbus perform several functions, their contributions to the proper maintenance and integrity of the corneal epithelium are critical.

Because corneal epithelium is highly differentiated cell type with rapid self renewal abilities, its stem cells should be readily available.Davanger and Evensen were possibly the first to postulate that limbal papillary structure serves as the generative organ for corneal epithelial cells. Kenyon and Tseng ultimately postulated that the stem cells are the most qualified cell to differentiate into normal corneal epithelium.

This stem cell hypothesis also has been extended to a pathogenetic concept of pterygium, where by the pterygium can be considered the consequence of "local stem cell deficiency". In particular, where as normal limbal tissue acts as a barrier between conjunctiva and cornea and thus prevents the invasion of subconjunctival tissue onto cornea. When this barrier function damaged by various insults like UV radiation or mechanical injuries, sub conjunctival cells are allowed to stream onto adjacent cornea, resulting in pterygium formation. Reestablishing normal barrier function by transplanting healthy limbal tissue may prevent this process. Based on this concept limbalautograft transplantation has recently been performed in cases with recurrent and advanced pterygia.

In this study, a recurrence rate of $4 \%$ was recorded. This is lower than the findings in other studies done by Kucukerdonmez et al., and Luanratanakorn et $\mathrm{al}^{(10,12)}$ which reported recurrence rates of $7.9 \%$ and $28.1 \%$ respectively. Even though similar in that these cohorts comprised both primary and recurrent pterygia these studies differed in study design, sample size and follow up period. While this study evaluated 50 eyes with primary pterygia who had pterygium excision with conjunctivalautograft, Kucukerdonmez et al and Luanratanakorn et al studied 38 and 287 eyes respectively. Kucukerdonmez et et al followed up their patients for 13.4 months (mean period) while follow- up period of this study was for 6 months.

Nakamura et $\mathrm{al}^{(13)}$ recorded no recurrence in their series. However this study had a longer mean follow- up period of $13.9 \pm 6$ months.

In the present study, only the minor post- operative Complications like transient graft edema, hemorrhage were reported. No significant sight- threatening complications were recorded. The low recurrence rate and favourable safety profile of pterygium excisionwith limbal stem cell transplantationin the current study attest to the efficacy of this treatment modality and It's results are superior to that of amniotic membrane graft and bare sclera.

\section{Conclusion}

No major post- operative complications following limbal stem cell transplantation in the present study agree with other reports that this procedure is effective and safe.The recurrence rate withlimbal stem celltransplantationis much lower than fresh amniotic membrane graft.Based on results of our study we agree that limbal stem cell transplantation will give less recurrence and better cosmetic appearance than amniotic membrane graft.And complications like foreign body sensation and watering are absent due to sutureless surgery with the help of blood clot to adhere graft to underlying sclera.But, due to the study's small sample size and a short period of follow- up, the findings should be interpreted with caution. A larger randomized controlled study will be required to confirm our findings.

\section{References}

[1]. Goldberg L, David R. Pterygium and its relationship to the dry eye in Bantu.Br J Ophthalmol 1976;60:720-1.

[2]. Alemworie M, Abebe B, Menen A. Prevalence of pterygium in a rural community of Meskan District, Southern Ethiopia. Ethio J Health Dev 2008;22:191-4.

[3]. Asokan R, Venkatasubbu RS, Velumuri L, Lingam V, George R. Prevalence and associated factors for pterygium and pingencula in South Indian Population.OphthalmicPhysiol Opt 2012;32:39-44.

[4]. Hirst LW. The treatment of pterygium. SurvOphthalmol 2003;48:145-177

[5]. Fernandes M, Sangwan VS, Gangopadhyay N, Sridhar MS, Garg P, AasuriMK,et al. Outcome of pterygium surgery: Analysis over 14 years. Eye,2005;19:1182-90.

[6]. Allan BD, Short P, Crawford GJ, Barret GD, Constable IJ. Pterygium excision with conjunctival autografting: An effective and safe technique. Br J Ophthalmol 1993;77:698-701.

[7]. Mastropasqua L, Carpineto P, Ciancaglini M, Enrico Gallenga P. Long term results of intraoperative mitomycin C in the treatment of recurrent pterygium. Br J Ophthalmol 1996;80:288-91

[8]. Buratto L, Phillips R L, Carito G. Pterygium surgery. NJ:SLACK: Slack Incorporated; 2000 
[9]. Ozer A, Yildirim N, Erol N, Yurdakul S. Long-term results of bare sclera, limbal-conjunctivalautograft and amniotic membrane graft techniques in primary pterygium excisions. Ophthalmol 2009;223:269-73.

[10]. Mutulu FM, Sobaci G, Tatar T, Yildirim E. A comparative study of recurrent pterygium surgery. Ophthalmology 1999;106:817821.

[11]. Lin CP, Shih MH, Tsai MC. Clinical experiences of infectious sclera ulceration: A complication of pterygium operation. $\mathrm{Br} \mathbf{J}$ Ophthalmol 1997;81:980-3.

[12]. Fernandes M, Sangwan VS, Gangopadhyay N, Sridhar MS, Garg P, Aasuri MK, et al. Outcome of pterygium surgery: Analysis over 14 years. Eye, 2005;19:1182-90.

[13]. Thoft RA, Friend J. The X, Y, Z hypothesis of corneal epithelial maintenance. Invest Ophthalmol Vis Sci.1983;24:1442-43.

[14]. Schermer A, Galvin S, Sun T-T. Differentiation-related expression of a major 64K corneal keratin in vivo and in culture suggests limbal location of corneal epithelial stem cells. J Cell Biol. 1986;103:49-62.

[15]. Puangsricharern V, Tseng SCG. Cytologic evidence of corneal diseases with limbal stem cell deficiency. Ophthalmology 1995;102:1476-85.

[16]. Dua HS, Saini TS, Azuara-Blanco A, Gupta P Limbal stem cell deficiency: Concept, aetiology, clinical presentation, diagnosis and management. Indian J Ophthalmol 2000;48:483-91.

[17]. Fujishima, H., Shimazaki, J. and Tsubota, K., 1996. Temporary corneal stem cell dysfunction after radiation therapy. Br. J. Ophthalmol. 80, pp. 911-914.

[18]. Espana, E.M., Raju, V.K. and Tseng, S.C., 2002. Focal limbal stem cell deficiency corresponding to an iris coloboma. Br. J. Ophthalmol.86, pp. 1451-1452

[19]. Espana, E.M., Grueterich, M., Romano, A.C., Touhami, A. and Tseng, S.C., 2002. Idiopathic limbal stem cell deficiency. Ophthalmology109, pp. 2004-2010.

[20]. Grueterich, M., Espana, E.M., Romano, A.C., Touhami, A. and Tseng, S.C.G., 2002. Surgical approaches for limbal stem cell deficiency. Contemp. Ophthalmol.1, pp. 1-18.

[21]. Wolosin, J.M., Schutte, M., Zieske, J.D. and Budak, M.T., 2002. Changes in connexin43 in early ocular surface development. Curr. Eye Res.24, pp. 430-438. 